\title{
FAM3A Protects Against Glutamate- Induced Toxicity by Preserving Calcium Homeostasis in Differentiated PC12 Cells
}

\author{
Qing Songa Wen-Li Gou ${ }^{a} \quad$ Yu-Liang Zou ${ }^{a}$ \\ aDepartment of Obstetrics and Gynecology, the First Affiliated Hospital, Xian Jiaotong University, Xi'an, \\ Shaanxi, China
}

\section{Key Words}

Fam3a • Mitochondrial dysfunction • Glutamate receptors $•$ Calcium homeostasis $•$ SOCE

\begin{abstract}
Background/Aims: Stroke is the leading cause of adult disability, and glutamate-induced dysregulation of intracellular $\mathrm{Ca}^{2+}$ homeostasis is a key mechanism. FAM3A is the first member of the family with sequence similarity 3 (FAM3) gene family, and its biological function remains largely unknown. We have recently reported that FAM3A exerts protective effects against oxidative stress and mitochondrial dysfunction in HT22 cells. Methods: Here, we investigated the protective effects of FAM3A using a glutamate-induced neuronal injury model in nerve growth factor (NGF)-differentiated PC12 cells. The protective effects were determined by measuring lactate dehydrogenase (LDH) release, apoptosis and mitochondrial oxidative stress. $\mathrm{Ca}^{2+}$ imaging was performed to detect changes in intracellular $\mathrm{Ca}^{2+}$ concentration in PC12 cells. The related molecular mechanisms were investigated by fluorescence staining, coimmunoprecipitation (Co-IP) and western blotting. Results: Upregulation of FAM3A by lentivirus transfection markedly decreased LDH release, inhibited apoptosis and reduced mitochondrial oxidative stress, which were accompanied by alleviated intracellular $\mathrm{Ca}^{2+}$ levels as measured by calcium imaging. The results of western blotting showed that FAM $3 \mathrm{~A}$ significantly decreased the surface expression of metabotropic glutamate receptor $1 / 5$ (mGluR1/5), with no effect on the expression of $\mathrm{N}$-methyl-d-aspartic acid receptor (NMDAR) or $\alpha$-amino-3-hydroxy-5-methyl-4-isoxazole-propionic acid receptor (AMPAR) subunits. FAM3A overexpression also inhibited the intracellular $\mathrm{Ca}^{2+}$ release mediated by mGluR1/5 and inositol 1,4,5-trisphosphate receptor $\left(\mathrm{IP}_{3} \mathrm{R}\right)$, but not the ryanodine receptor (RyR). In addition, FAM3A significantly attenuated the store-operated calcium entry (SOCE) induced by thapsigargin (Tg), but the expression of SOCE-related proteins was not altered. The results of coimmunoprecipitation (Co-IP) showed that FAM3A disrupted the interaction of stromal interaction molecule 1 (STIM1) with Orai1 triggered by glutamate. Conclusion: These results suggest that the upregulation of FAM3A protects against glutamate-induced dysfunction of $\mathrm{Ca}^{2+}$ homeostasis not only by inhibiting mGluR1/5-dependent endoplasmic reticulum (ER) $\mathrm{Ca}^{2+}$ release, but also by attenuating SOCE mediated by the STIM1-Orai1 interaction.
\end{abstract}




\section{Cellular Physiology Cell Physiol Biochem 2017;44:2029-2041 \begin{tabular}{ll|l} 
and Biochemistry Published online: December 12, 2017 & $\begin{array}{l}\text { (c) } 2017 \text { The Author(s). Published by S. Karger AG, Basel } \\
\text { www.karger.com/cpb }\end{array}$
\end{tabular}

\section{Introduction}

The world is facing an epidemic of stroke, and approximately 17 million people experience a first-time stroke each year [1]. Although extraordinary advances in stroke treatment and prevention have been achieved in the past decade, the exact molecular mechanisms underlying neuronal injury after stroke are not fully determined. Excessive release of glutamate and subsequent oxidative stress are well-known key biochemical events that promote ischemic neuronal damage through various signaling cascades [2, 3]. The calcium ion $\left(\mathrm{Ca}^{2+}\right)$ is a key regulator of many physiological cellular processes, such as cell growth and differentiation, neurotransmitter release and synaptic plasticity [4]. The normal concentration of free intracellular $\mathrm{Ca}^{2+}$ is approximately $100 \mathrm{mM}$ compared to $1 \mathrm{mM}$ in the extracellular space [5]. $\mathrm{Ca}^{2+}$ overload, a process induced by prolonged increase in intracellular $\mathrm{Ca}^{2+}$ concentration, might be detrimental for neurons, and is also a molecular mechanism that contributes to glutamate-induced neuronal injury after stroke [6]. Glutamate regulates intracellular $\mathrm{Ca}^{2+}$ homeostasis via two distinct mechanisms, one is the $\mathrm{Ca}^{2+}$ influx from the extracellular space through ionotropic glutamate receptors (iGluRs) and other agonist-gated $\mathrm{Ca}^{2+}$ channels, and the other is the $\mathrm{Ca}^{2+}$ release from the endoplasmic reticulum (ER) via metabotropic glutamate receptors (mGluRs) signaling $[7,8]$. The neuroprotective effects of the modulators of these receptors have been demonstrated by both in vitro and in vivo experiments $[9,10]$.

The family with sequence similarity 3 (FAM3) gene family is a cytokine-like gene family that is ubiquitously expressed in most human and rodent tissues [11]. So far, four members of FAM3 have been identified in mammalians: FAM3A, FAM3B, FAM3C and FAM3D, which share approximately 31.6\%-53.3\% homology at the amino acid level [12]. Most of previous studies of FAM3 are focused on FAM3B, which is also known as pancreatic-derived factor (PANDER) due to its high abundance in pancreatic islets [13]. However, the physiological and potential pathological roles of FAM3A are not fully determined. Previous studies showed that FAM3A activates the $\mathrm{PI}_{3} \mathrm{~K} /$ Akt pathway to ameliorate hepatic gluconeogenesis and lipogenesis [14], and that upregulation of FAM3A contributes to peroxisome proliferatoractivated receptor $\gamma$ (PPAR- $\gamma$ )-induced metabolic effects in the liver [15]. Our previous study showed that FAM3A has protective effects against $\mathrm{H}_{2} \mathrm{O}_{2}$-induced oxidative stress by reducing ROS accumulation and apoptosis in neuronal HT22 cells [16]. We also found that FAM3A could regulate the crosstalk between the ER and mitochondria via CHOP-Wnt signaling [17]. These data indicate that FAM3A might be a key regulator of neuronal survival in neurological diseases. The PC12 cell, an immortalized adrenal pheochromocytoma cell line, is a good model for neural differentiation and neurosecretion studies [18]. It can be differentiated with nerve growth factor (NGF) to better resemble a neuronal phenotype [19], thereby allowing for applications in neuropharmacological and neurotoxicological studies. Here, we used a glutamate-induced neuronal injury model in NGF-differentiated PC12 cells to explore the possible protective effects of FAM3A against oxidative stress injury. We also investigated the potential underlying mechanisms with a focus on intracellular $\mathrm{Ca}^{2+}$ homeostasis.

\section{Materials and Methods}

Cell culture

Rat pheochromocytoma PC12 cells were purchased from the Institute of Biochemistry and Cell Biology, and cultured in Dulbecco's modified Eagle's medium (DMEM) with $10 \%$ fetal bovine serum at $37^{\circ} \mathrm{C}$. For differentiation, PC12 cells were seeded onto poly-L-lysine (PLL) pre-coated plates and treated with $50 \mathrm{ng} /$ ml NGF for 7 days. 


\section{Cellular Physiology Cell Physiol Biochem 2017;44:2029-2041 \begin{tabular}{ll|l} 
and BiOChemistry & $\begin{array}{l}\text { DOI: 10.1159/000485943 } \\
\text { Published online: December 12, } 2017\end{array}$ & $\begin{array}{l}\text { (c) } 2017 \text { The Author(s). Published by S. Karger AG, Basel } \\
\text { www.karger.com/cpb }\end{array}$ \\
\hline
\end{tabular}}

pGC-FU plasmid were digested with Age I and then ligated with T4 DNA ligase to produce pGC-FU-FAM3A. To generate the recombinant Lentivirus LV- FAM3A, 293T cells were co-transfected with a pGC-FU plasmid $(20 \mu \mathrm{g})$ with cDNA encoding FAM3A, pHelper1.0 plasmid $(15 \mu \mathrm{g})$ and pHelper 2.0 plasmid $(10 \mu \mathrm{g}) \mathrm{using}$ Lipofectamine $2000(100 \mu \mathrm{l})$. After $48 \mathrm{~h}$, the supernatant was harvested, and the viral titer was calculated by transducing 293T cells. We also generated a control lentiviral vector that expressed GFP alone (LV-control).

Cellular toxicity assays

Glutamate-induced toxicity in differentiated PC12 cells was determined by flow cytometry and lactate dehydrogenase (LDH) release assay as previously described [16, 20].

\section{Mitochondrial oxidative stress assay}

The reporter gene Mito-Timer was used to measure the mitochondrial oxidation level. The images in green (488/518 nm) and red (543/572 nm) channels were detected by a fluorescence microscope.

\section{$\mathrm{Ca}^{2+}$ imaging}

Intracellular $\mathrm{Ca}^{2+}$ concentration was measured using the calcium indicator Fura-2-AM. Differentiated PC12 cells grown on glass slides were loaded with $5 \mu \mathrm{M}$ Fura-2 AM for 45 min in Hanks Balanced Salt Solution (HBSS), and equilibrated for $30 \mathrm{~min}$ in the dark at room temperature. Cells were then placed in an open-bath imaging chamber containing HBSS. Using a Nikon inverted epifluorescence microscope, neurons were excited at 345 and $385 \mathrm{~nm}$ and the emission fluorescence at $510 \mathrm{~nm}$ was recorded. Images were collected and analyzed with the MetaFluor image-processing software, and the results were calculated and reported as $\mathrm{F}_{\mathrm{t}} / \mathrm{F}_{0}$ and area under curve (AUC).

\section{Surface biotinylation assay}

The surface biotinylation assay was performed using the Pierce Cell Surface Isolation Kit according to the manufacturer's instructions (Thermo Scientific). Samples were used to perform biochemical studies and western blotting.

\section{Electrophysiology}

Whole-cell recordings were performed following standard procedures using an EPC9 patch clamp amplifier as described previously [21]. Imaging of transient $\mathrm{Ca}^{2+}$ changes in PC12 cells was started 25-30 min after establishing the whole-cell configuration. A multipoint confocal microscope using dual spinning disc technology, attached to an upright microscope and equipped with a 403 objective was used to acquire fluorescence images in parallel with the patch clamp recordings.

\section{$I P_{3}$ uncaging}

For photolytic uncaging experiments, the internal saline was supplemented with NPE-IP3 (400 mM; Invitrogen). Uncaging of $\mathrm{IP}_{3}$ was produced by directing the output of a diode laser (Coherent Cube; $375 \mathrm{~nm}$, $15 \mathrm{~mW}$ at the laser head) onto the surface of the cultures with the use of a tapered lensed optical fiber [21].

\section{Real-time RT-PCR}

Total RNA was used to synthesize the first strand of cDNA using a reverse transcription kit (Takara, Dalian, China). The mRNA levels of SOCE related molecules were quantified using a Bio-Rad iQ5 Gradient Real-Time PCR system (Bio-Rad Laboratories), and GAPDH was used as an endogenous control. Primers for all Real-Time PCR experiments were as follow: STIM1: forward: 5'- AGG AGC CTC ATC CTA ATC TCA CTC A -3', reverse: 5'- GGC ATC CAC TCA TGC TCC AA -3'; STIM2: forward: 5'- TCT GTC CCT GAC GCA CTA CAG AA -3', reverse: 5'- ACG TGC AGG GTC CCA AAG A -3'; Orai1: forward: 5' - ATG TCA CTG AGT CCA CCA TGC TTT A -3', reverse: 5'- TCT CTG TGC AGA TGG CTG TGT TTA -3'; GAPDH: forward: 5'-AAG GTG AAG GTC GGA GTC AA -3', reverse: 5' - AAT GAA GGG GTC ATT GAT GG -3'.

\section{Immunocytochemistry (ICC)}

PC12 cells were fixed with 4\% paraformaldehyde and incubated with blocking solution (PBS containing $1 \%$ bovine serum albumin, $0.4 \%$ Triton X-100 and 4\% normal goat serum) for 20 min. Next, cells were incubated with primary antibodies (anti-FAM3A, 1:500; anti-STIM1, 1:800) at $4^{\circ} \mathrm{C}$ overnight. The cells were 


\section{Cellular Physiology Cell Physiol Biochem 2017;44:2029-2041 \begin{tabular}{l|l|l} 
and Biochemistry Published onlIne: December 12, 2017 & $\begin{array}{l}\text { (c) } 2017 \text { The Author(s). Published by S. Karger AG, Basel } \\
\text { www.karger.com/cpb }\end{array}$ \\
\hline
\end{tabular}

then incubated with fluorescein isothiocyanate (FITC) labeled secondary antibody (1:600; goat anti-rabbit) for $1 \mathrm{~h}$ at room temperature. DAPI (blue) was used to stain nuclei.

Coimmunoprecipitation (Co-IP)

Co-IP experiments were performed using the Pierce ${ }^{\mathrm{TM}}$ Crosslink Magnetic Co-IP Kit, according to the manufacturer's instructions (Pierce USA). Magnetic beads were crosslinked with non-specific rabbit or goat IgG (2 mg), poly-clonal rabbit anti-STIM1 (1:30; CST), or goat anti-FAM3A (1:30; Santa Cruz), and then the beads were washed two times with coupling buffer. The protein extracts combined with the beads were incubated overnight at $4^{\circ} \mathrm{C}$. Following magnetic isolation, the precipitates were eluted with elution buffer, neutralized with neutralization buffer, and prepared for western blotting.

\section{Western blotting analysis}

Forty micrograms of protein was resolved on $12 \%$ SDS-PAGE gel and transferred onto PVDF membranes. Membranes were blocked with $5 \%$ skimmed milk solution and incubated overnight at $4{ }^{\circ} \mathrm{C}$ with the primary antibodies NR1, NR2A, NR2B, GluR1, GluR2, mGluR1/5, STIM1, STIM2, Orai1 or $\beta$-actin diluted in TBST. The membranes were then washed and incubated with secondary antibody for $1 \mathrm{~h}$. Immunoreactivity was detected with Super Signal West Pico Chemiluminescent Substrate (Thermo Scientific, Rockford, IL, USA). ImageJ (Scion Corporation) was used to quantify the optical density of each band.

\section{Statistical analysis}

Statistical analysis was performed using SPSS 16.0. Statistical evaluations of data were performed by one-way analysis of variance (ANOVA) followed by Bonferroni's multiple comparisons.

\section{Results}

FAM3A alleviates glutamate-induced toxicity in NGF-differentiated PC12 cells

To investigate the potential protective effect of FAM3A against glutamate-induced toxicity, differentiated PC12 cells were transfected with lentivirus expressing FAM3A (LVFAM3A) or control lentivirus (LV-control). The results of western blotting showed that LVFAM3A transfection significantly increased the expression of FAM3A protein compared to that of the LV-control group (Fig. 1A). Overexpression of FAM3A significantly decreased LDH release after glutamate treatment (Fig. 1B), and the glutamate-induced apoptosis was markedly attenuated by LV-FAM3A transfection (Fig. 1C). Next, we used a novel reporter gene to measure mitochondrial oxidative stress in differentiated PC12 cells. As shown in Fig. 1C, an overall increase in the red/green ratio was found in glutamate-treated cells, indicating the increased protein oxidation. Following FAM3A overexpression, the red/green ratio was significantly reduced compared to that in LV-control transfected cells.

\section{FAM3A inhibits intracellular $\mathrm{Ca}^{2+}$ overload after glutamate treatment}

To investigate the effect of FAM3A on intracellular $\mathrm{Ca}^{2+}$ homeostasis after glutamate treatment, we monitored intracellular $\mathrm{Ca}^{2+}$ concentrations with the ratiometric $\mathrm{Ca}^{2+}$ indicator Fura-2AM. Fig. 2A shows the dynamic changes of $\mathrm{Ca}^{2+}$ concentrations expressed as a fold of baseline up to $24 \mathrm{~h}$. Glutamate treatment led to significant increases in $\mathrm{Ca}^{2+}$ concentrations in both LV-control and LV-FAM3A transfected PC12 cells, and the increases were seen with respect to both amplitude and duration. However, the overexpression of FAM3A markedly lowered peak amplitude ( $5.33 \pm 0.43$ vs. $2.86 \pm 0.24, \mathrm{n}=5, p<0.05)$. In addition, we also calculated the AUC for $\mathrm{Ca}^{2+}$ concentration to assay $\mathrm{Ca}^{2+}$ changes over $24 \mathrm{~h}$, and the results showed that FAM3A significantly reduced the AUC by approximately $55 \%$ compared to the LV-control group.

Effects of FAM3A on glutamate receptor expression

Glutamate receptors play important roles in glutamate-induced $\mathrm{Ca}^{2+}$ regulation, and their functions are largely dependent on their cell surface expression. Thus, we detected the 


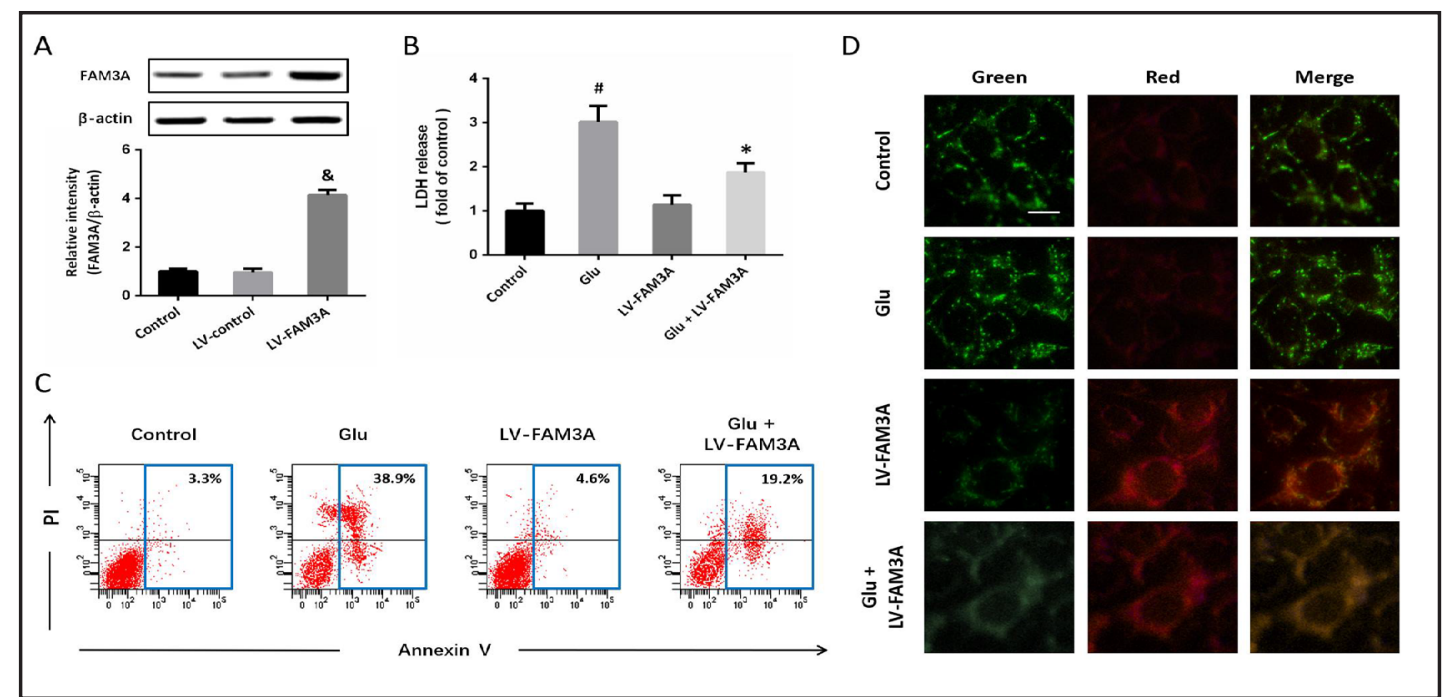

Fig. 1. FAM3A alleviates glutamate-induced toxicity in NGF-differentiated PC12 cells. NGF-differentiated PC12 cells were transfected with a lentivirus expressing FAM3A (LV-FAM3A) or a control lentivirus (LVcontrol) for $72 \mathrm{~h}$, and the expression of FAM3A was detected by western blotting (A). After lentivirus transfection, the cells were treated with glutamate, and the LDH release (B) and apoptosis (C) were measured at $24 \mathrm{~h}$ later. Mitochondrial oxidative stress was detected by the pMito Timer plasmid transfection (C). Scale bars: $10 \mu \mathrm{m}$. Data are shown as the mean \pm SEM. ${ }^{\circledR} \mathrm{p}<0.05$ vs. LV-control. ${ }^{\#} \mathrm{p}<0.05$ vs. control. ${ }^{*} \mathrm{p}<0.05$ vs. glutamate.

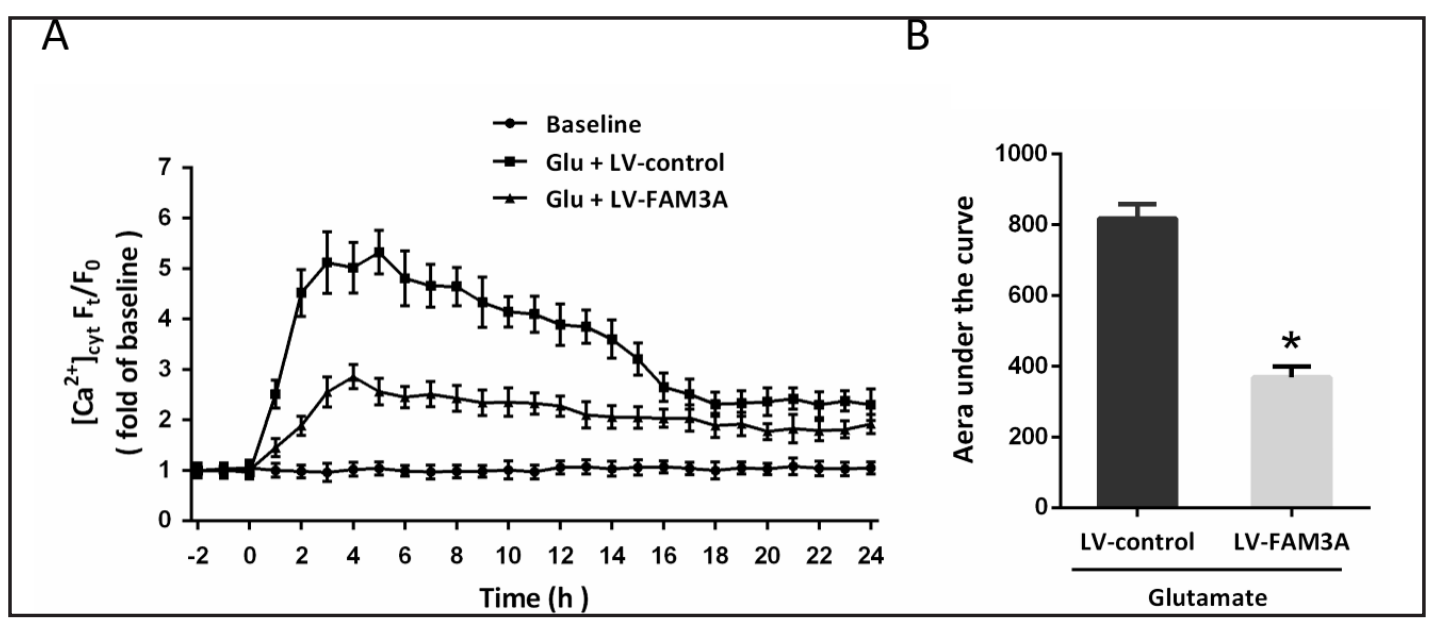

Fig. 2. FAM $3 \mathrm{~A}$ inhibits intracellular $\mathrm{Ca}^{2+}$ overload after glutamate treatment. Differentiated PC12 cells were transfected with LV-FAM3A or LV-Control for $72 \mathrm{~h}$ and treated with $5 \mathrm{mM}$ glutamate. The intracellular $\mathrm{Ca}^{2+}$ concentration $\left(\left[\mathrm{Ca}^{2+}\right]_{\mathrm{cyt}}\right)$ was determined by Fura-2AM up to $24 \mathrm{~h}(\mathrm{~A})$, and the total area under the curve of each phase was calculated (B). Data are shown as the mean \pm SEM. ${ }^{*} \mathrm{p}<0.05$ vs. LV-control.

total and surface expression of glutamate receptors and receptor subunits using western blotting. As shown in Fig. 3A-3C, FAM3A overexpression had no effect on either the total or surface expression of NR1, NR2A or NR2B, three subunits of the NMDA receptor. Similar results were also observed on the expression of AMPA receptor subunits GluR1 and GluR2 (Fig. 3D and 3E). However, the overexpression of FAM3A significantly reduced the surface expression of mGluR1/5, with no effect on total protein levels (Fig. 3F). 


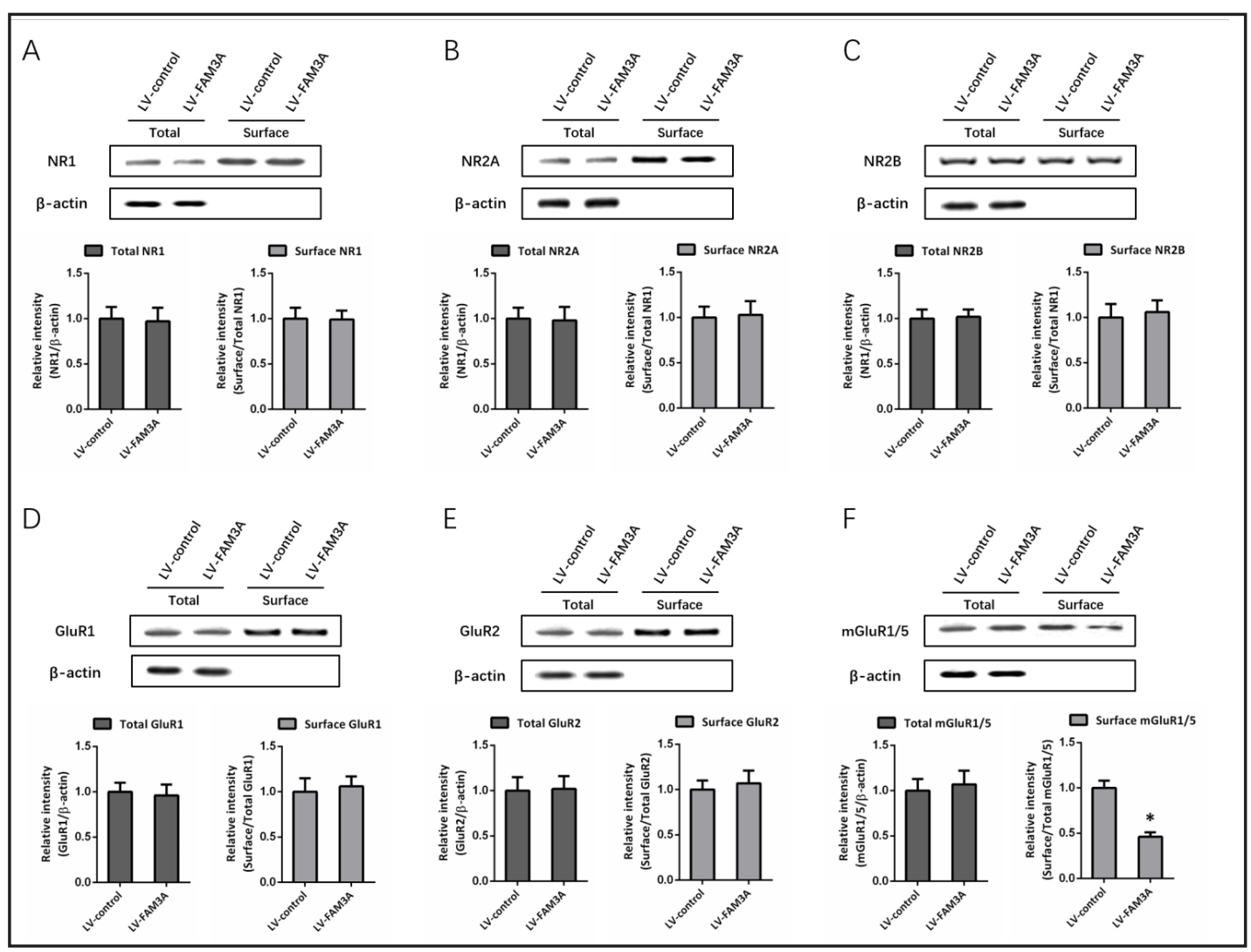

Fig. 3. Effects of FAM3A on the expression of glutamate receptors. Differentiated PC12 cells were transfected with LV-FAM3A or LV-Control for $72 \mathrm{~h}$ and treated with $5 \mathrm{mM}$ glutamate. The total and surface expression of NMDA receptor subunits (NR1, NR2A and NR2B, A-C), AMPA receptor subunits (GluR1 and GluR2, D and E), and group I mGluRs (mGluR1/5, F) were detected by western blotting. Data are shown as the mean \pm SEM. ${ }^{*}$ p $<0.05$ vs. LV-control.

\section{FAM3A attenuates ER Ca ${ }^{2+}$ release through $m G l u R 1 / 5-I P_{3} R$ pathway}

To confirm the involvement of FAM3A in mGluR1/5-mediated $\mathrm{Ca}^{2+}$ release from the ER, differentiated PC12 cells were treated with the mGluR1/5 agonist DHPG after transfection with LV-FAM3A or LV-control for $72 \mathrm{~h}$ (Fig. 3A). The results showed that the application of DHPG produced a local $\mathrm{Ca}^{2+}$ transient in LV-control transfected cells, but not in LV-FAM3A transfected cells (Fig. 3B). In addition, we also tested the responsiveness of $\mathrm{ER} \mathrm{Ca}^{2+}$ to $\mathrm{IP}_{3}$ by photolysis of NPE-caged IP ${ }_{3}$ using optical fibers to deliver UV pulses (Fig. 4C). This stimulation produced large $\mathrm{Ca}^{2+}$ transients in LV-control transfected cells but only small transients in the LV-FAM3A group (Fig. 4D). In contrast, the application of the RyR agonist caffeine induced large $\mathrm{Ca}^{2+}$ transients in both LV-control and LV-FAM3A groups (Fig. 3E), with no significant differences between groups (Fig. 4F).

\section{Effects of FAM3A on SOCE and expression of SOCE-related proteins}

SOCE is a dynamic $\mathrm{Ca}^{2+}$-regulating mechanism for both $\mathrm{Ca}^{2+}$ influx and release. Thus, we further measured the effects of FAM3A overexpression on SOCE induced by Tg, which caused a significant $\mathrm{Ca}^{2+}$ release from the ER in the absence of extracellular $\mathrm{Ca}^{2+}$, followed by $\mathrm{Ca}^{2+}$ influx immediately after restoration of extracellular $\mathrm{Ca}^{2+}$ in control cells (Fig. 5A). Transfection with LV-FAM3A significantly reduced $\mathrm{Ca}^{2+}$ influx after $\mathrm{Ca}^{2+}$ restoration, but did not affect ER $\mathrm{Ca}^{2+}$ release (Fig. 5B). In addition, we also detected the expression of STIM1, STIM2 and Oria1, three SOCE-related proteins. The results of RT-PCR and western blotting analysis showed that the mRNA (Fig. 5C) and protein (Fig. 5D) levels of these molecules were not altered by FAM3A compared with the LV-control group. 
Fig. 4. FAM $3 A$ attenuates $\mathrm{ER} \mathrm{Ca}^{2+}$ release through the mGluR1/5-IP $\mathrm{R}$ pathway. Differentiated PC12 cells were transfected with LVFAM3A or LV-Control for 72 h. Relative changes in $\mathrm{Ca}^{2+}$ responses $(\Delta \mathrm{F} / \mathrm{F})$ to the application of DHPG $(200 \mu \mathrm{M}, \mathrm{A})$, to the photolysis of caged $\mathrm{IP}_{3}(\mathrm{C})$, or to the application of caffeine (80 $\mathrm{mM}, \mathrm{E}$ ) in LV-control (blue, left) and LV-FAM3A group (red, right) were detected. Summaries of the $\mathrm{Ca}^{2+}$ responses experiments was shown in B, D and F. Data are shown as the mean \pm SEM. ${ }^{\text {p }}<0.05$ vs. LV-control.

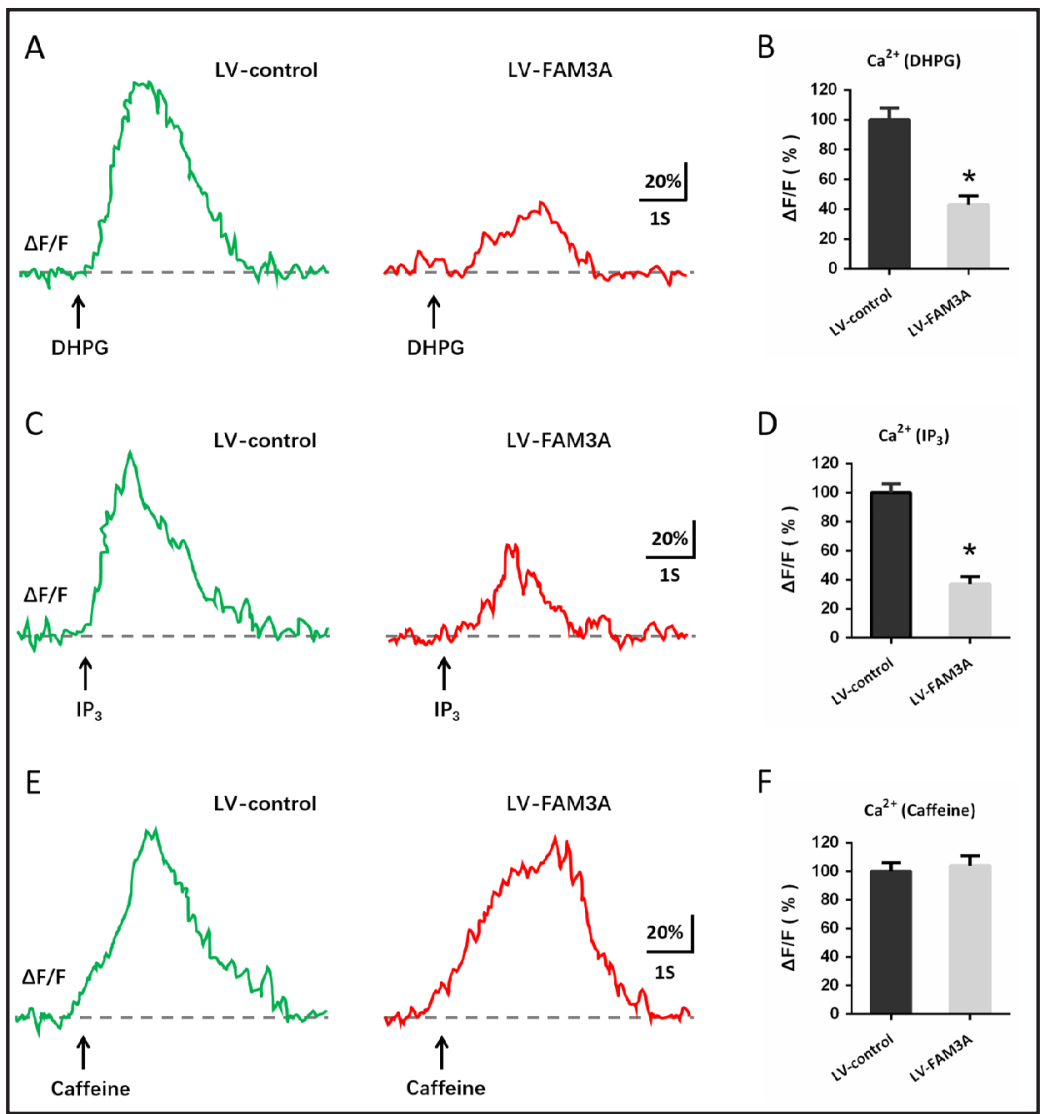

Fig. 5. Effects of FAM3A on SOCE and expression of SOCE-related proteins. Differentiated PC12 cells were transfected with LVFAM3A or LV-Control for 72 h. Calcium imaging using the " $\mathrm{Ca}^{2+}$-off and $\mathrm{Ca}^{2+}$-on" protocol with the application of $\mathrm{Tg}(2 \mu \mathrm{M})$ was used to determine SOCE (A), and the total area under the curve of each phase was calculated (B). The expression of STIM1, STIM2 and Orai1 mRNA levels was measured by RT-PCR (C), and the expression of these SOCE-related proteins was detected by western blotting (D). Data are shown as the mean \pm SEM. ${ }^{*} \mathrm{p}<0.05$ vs. LV-control.
A

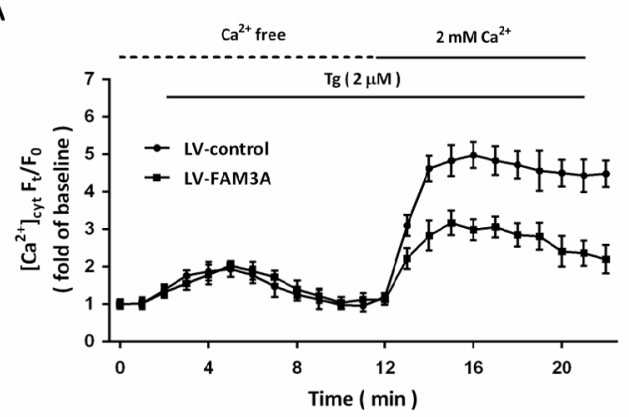

B

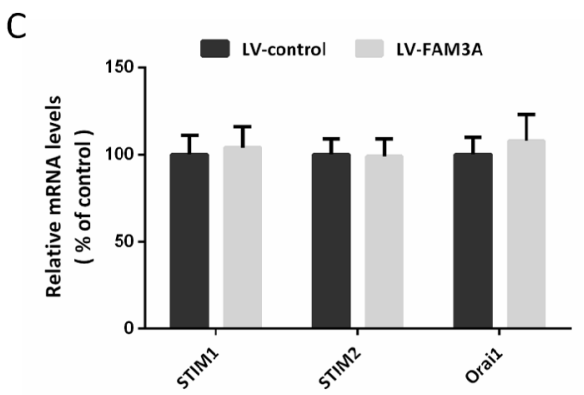

D
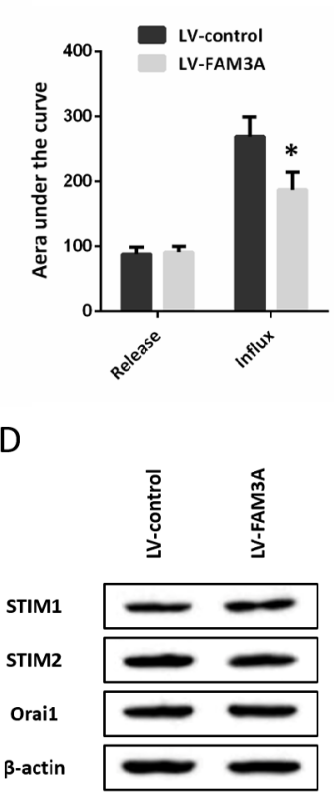


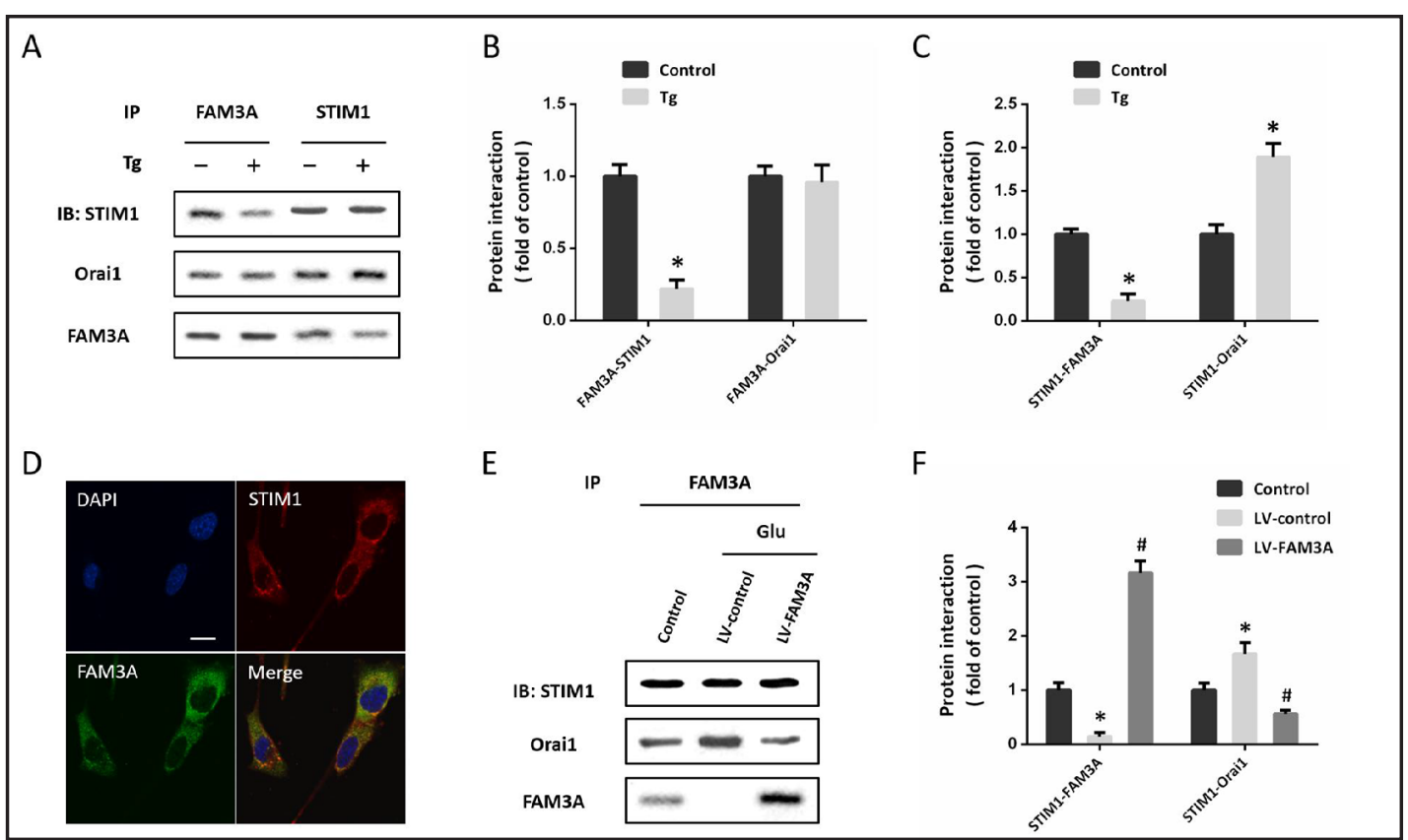

Fig. 6. FAM3A inhibits SOCE by regulating the STIM1-Orai1 interaction. Differentiated PC12 cells were treated with $\operatorname{Tg}(2 \mu \mathrm{M})$ for $1 \mathrm{~h}$, and Co-IP was performed using STIM1, Orai1 and FAM3A antibodies (A). The formation of FAM3A-STIM1 and FAM3A-Orai1 complexes was quantified (B and C). Fluorescence staining was performed using STIM1 (red), FAM3A (green) antibodies and DAPI (blue) to detect the co-localization of FAM3A and STIM1 (D). Differentiated PC12 cells were transfected with LV-FAM3A or LV-Control for 72 $\mathrm{h}$ and treated with $5 \mathrm{mM}$ glutamate. Co-IP was performed using STIM1, Orai1 and FAM3A antibodies (E), and the interaction of STIM1 with FAM3A or Orai1 was quantified (F). Data are shown as the mean \pm SEM. ${ }^{\#} \mathrm{p}<0.05$ vs. control. ${ }^{*} \mathrm{p}<0.05$ vs. LV-control.

\section{FAM3A inhibits SOCE by regulating the STIM1-Orai1 interaction}

To determine whether FAM3A disrupts the interaction between STIM1 and Orai1, CoIP experiments were performed using both control and Tg-treated PC12 cells (Fig. 6A). As shown Fig. 6B and 6C, tight interactions of FAM3A, STIM1 and Orai1 were observed in control cells. In Tg-treated PC12 cells, a significant decrease in the interaction of FAM3A with STIM1 (Fig. 6B) and an increase in the interaction of STIM1 with Orai1 were detected (Fig. 6C). However, Tg treatment had no effect on the Co-IP of FAM3A with Orai1 (Fig. 6B). The results of fluorescence staining also confirmed the co-localization of FAM3A and STIM1 in the cytoplasm of PC12 cells (Fig. 6D). In addition, we investigated the effect of FAM3A overexpression on the interaction between STIM1 and Orai1 after glutamate treatment (Fig. $6 \mathrm{E})$. The results showed that LV-FAM3A transfection markedly attenuated the formation of STIM1-Orai1 complexes compared with the LV-control group (Fig. 6F).

\section{Discussion}

It has been shown that FAM3B is highly expressed in the pancreas, FAM3D in the placenta, and FAM3A and FAM3C in almost all tissues. Most previous studies of FAM3 are focused on FAM3B, which has been shown to be involved in the pathogenesis of type 2 diabetes and hepatic insulin sensitivity [22]. We have recently reported that FAM3A exerts protective effects against oxidative stress and mitochondrial dysfunction in neuronal HT22 cells $[16,17]$. Another research group found that FAM3A protects against liver ischemiareperfusion injury via Akt-mediated inhibition of oxidative stress and inflammation [23], 


\section{Cellular Physiology Cell Physiol Biochem 2017;44:2029-2041 \\ \begin{tabular}{l|l} 
DOI: 10.1159/000485943 & $\begin{array}{l}\text { O 2017 The Author(s). Published by S. Karger AG, Basel } \\
\text { www.karger.com/cpb }\end{array}$
\end{tabular} \\ Song et al.: FAM3A Regulates $\mathrm{Ca}^{2+}$ Homeostasis in NGF-Differentiated PC12 Cells}

and plays an important role in in the development of adipose dysfunction and type 2 diabetes [24]. Here, we confirmed the protective activities of FAM3A in glutamate-induced toxicity in differentiated PC12 cells, an in vitro model with a better neuronal phenotype. More importantly, we found that FAM3A is an essential coordinator of intracellular $\mathrm{Ca}^{2+}$ homeostasis. On one hand, FAM3A inhibited intracellular $\mathrm{Ca}^{2+}$ release by suppressing the surface expression of mGluR1/5. On the other hand, FAM3A disrupted the protein-protein interaction between STIM1 and Oria1, thereby reducing $\mathrm{Ca}^{2+}$ influx through SOCE.

It is well documented that most of the damage caused by glutamate is attributed to disturbances in intracellular $\mathrm{Ca}^{2+}$ homeostasis [25]. Increased levels of intracellular $\mathrm{Ca}^{2+}$ accumulate within mitochondria causing metabolic failure and oxidative stress, which in turn lead to neuronal apoptosis or necrosis. Attenuating intracellular $\mathrm{Ca}^{2+}$ overload is thus essential for limiting neuronal cell death under both acute and chronic neuropathological conditions [26]. In this study, a very rapid and prolonged rise in intracellular $\mathrm{Ca}^{2+}$ concentration was observed after glutamate treatment. In LV-FAM3A transfected cells, these increases in intracellular $\mathrm{Ca}^{2+}$, with respect to both amplitude and duration, were significantly attenuated compared to the LV-control group, indicating the suppression of intracellular $\mathrm{Ca}^{2+}$ overload. Among distinct glutamate receptors, the NMDA receptor plays a vital role in intracellular $\mathrm{Ca}^{2+}$ regulation. Influx through NMDA receptor causes activation of nitric oxide synthase (NOS) and NO release, leading to the formation of superoxide, peroxynitrite and hydroxyl radicals $[27,28]$. To date, many selective NMDA receptor antagonists have been shown to exert neuroprotective effects $[29,30]$. Intriguingly, our results showed that FAM3A overexpression had no effect on the expression of NR1, NR2A or NR2B, three subunits of NMDA receptors. Additionally, the expression of AMPA receptor subunits, GluR1 and GluR2, was not altered. Combined, these data suggest that FAM3A-induced inhibition of intracellular $\mathrm{Ca}^{2+}$ overload might be mediated in an iGluRs-independent manner.

In neuronal cells, glutamate-induced regulation of $\mathrm{Ca}^{2+}$ homeostasis is also associated with mGluRs, which cause the mobilization of $\mathrm{Ca}^{2+}$ from internal stores via GTP-binding protein (G-protein)-dependent mechanisms [31-33]. The function of mGluRs is largely dependent on the multi-protein complexes formed with other adaptor proteins and the cell surface expression of these receptors [34, 35]. Thus, we also detected the expression of mGluR1/5 using western blotting. As expected, LV-FAM3A transfection significantly decreased the surface expression of mGluR1/5 protein, with no effects on total protein levels, indicating the potential involvement of mGluRs signaling in FAM3A-induced $\mathrm{Ca}^{2+}$ regulation. In line with these data, the application of the mGluR1/5 agonist DHPG produced an inward current and local $\mathrm{Ca}^{2+}$ transient in LV-control, but not in LV-FAM3A transfected cells. These results strongly indicate that FAM3A-induced $\mathrm{Ca}^{2+}$ regulation is partly mediated by an inhibition in mGluR1/5 signaling. Activation of mGluR1/5 promotes $\mathrm{ER} \mathrm{Ca}^{2+}$ release via various ER-resident channels, such as inositol 1, 4,5-trisphosphate receptors (IP ${ }_{3} \mathrm{Rs}$ ) and ryanodine receptors (RyRs) [36-38]. We further tested the responsiveness of $\mathrm{ER} \mathrm{Ca}^{2+}$ stores to IP $\mathrm{I}_{3}$ by photolysis of NPE-caged $\mathrm{IP}_{3}$ using optical fibers to deliver UV pulses. In the presence of FAM3A overexpression, ER stores became largely devoid of $\mathrm{Ca}^{2+}$ and $\mathrm{IP}_{3}$ failed to produce $\mathrm{C} \mathrm{Ca}^{2+}$ release signal from the ER. In contrast, the application of the RyR agonist caffeine produced large $\mathrm{Ca}^{2+}$ transients in both control and FAM3A overexpressed cells. Since $\mathrm{IP}_{3} \mathrm{R}$-mediated ER $\mathrm{Ca}^{2+}$ release and $\mathrm{Ca}^{2+}$ uptake into mitochondria are tightly coupled [39], we speculated that FAM3A could affect cell damage through mGluR1/5-IP ${ }_{3}$ mediated ERmitochondria signaling after glutamate treatment.

There are two major mechanisms responsible for glutamate-induced cytoplasmic $\mathrm{Ca}^{2+}$ signals, one is $\mathrm{Ca}^{2+}$ influx from the extracellular space via agonist-gated $\mathrm{Ca}^{2+}$ channels (including iGluRs), and the other is the $\mathrm{Ca}^{2+}$ release from the ER through mGluRs pathways. A process linking these two mechanisms is store-operated $\mathrm{Ca}^{2+}$ entry (SOCE), whereby the depletion of $\mathrm{ER} \mathrm{Ca}^{2+}$ store activates the opening of plasma membrane $\mathrm{Ca}^{2+}$ channels [40]. SOCE was originally thought to provide direct $\mathrm{Ca}^{2+}$ signals to recipients localized to spatially restricted areas close to the sites of $\mathrm{Ca}^{2+}$ entry to initiate specific signaling pathways. Recently, accumulating evidence suggest a key role of SOCE in neuronal survival and death. 


\section{Cellular Physiology Cell Physiol Biochem 2017;44:2029-2041 \begin{tabular}{ll|l} 
DOI: 10.1159/000485943 & $\begin{array}{l}\text { O 2017 The Author(s). Published by S. Karger AG, Basel } \\
\text { www.karger.com/cpb }\end{array}$
\end{tabular}

In a diffuse axonal injury model, abnormal SOCE was shown to participate in $\mathrm{Ca}^{2+}$ overload of neurons by inducing STIM1 expression [41]. A previous study found that SOCE play a role in the regulation of mitochondrial shape, bioenergetics and oxidative stress in mouse embryonic fibroblasts [42]. More recently, a blockage of SOCE by pharmacological inhibitors was demonstrated to protect neuronal $\mathrm{HT} 22$ cells from $\mathrm{H}_{2} \mathrm{O}_{2}$-induced apoptosis [43]. Our results showed that Tg-induced SOCE in PC12 cells was significantly attenuated by FAM3A overexpression, which was accompanied by reduced apoptosis. Using the same cell line, a previous study showed that inhibition of SOCE attenuated 1-methyl-4-phenylpyridinium $\left(\mathrm{MPP}^{+}\right)$-induced oxidative stress by inhibiting mitochondrial dysfunction [44]. Thus, we speculated that the overexpression of FAM3A partially prevented SOCE-mediated $\mathrm{Ca}^{2+}$ influx, thereby promoting cell survival in vitro.

SOCE is a process that involves two essential key players: STIM1, $\mathrm{a} \mathrm{Ca}^{2+}$ sensor localized to the ER, and Orai1, a $\mathrm{Ca}^{2+}$ selective channel in the plasma membrane [45]. Physiologically, when the tandem EF hand of STIM1 is bound with $\mathrm{Ca}^{2+}$, and STIM1 has a compact structure and uniform distribution. Upon $\mathrm{Ca}^{2+}$ store depletion, STIM1 undergoes a massive conformational transition to form the STIM1-Orai1 complex, which induces co-clustered puncta in the plasma membrane, leading to $\mathrm{Ca}^{2+}$ influx from the extracellular spaces $[46,47]$. Previous studies using RNAi knockdown have demonstrated the indispensable requirement of both STIM1 and Orai1 in SOCE regulation [48]. In this study, an increased interaction between STIM1 with Orai1 was also found after Tg treatment in differentiated PC12 cells, indicating STIM1Orai 1 complex formation in our in vitro model. It has been shown that many other proteins, such as adenylyl cyclase type 8 (AC8) [49], caveolin [50,51] and the L-type $\mathrm{Ca}^{2+}$ channel (Cav1.2) [52,53], couple or interplay with STIM1 and/or Orai1 to function in a modulatory manner within the SOCE signaling. Here, our results showed that in response to Tg treatment, the interaction between STIM1 and Orai1 increased, while the interaction between STIM1 and FAM3A decreased, with no apparent effect on the FAM3A-Orai1 complex. In addition, the interaction between STIM1 and Orai1 after glutamate exposure was significantly attenuated by LV-FAM3A transfection. All these data strongly suggest that FAM3A might be a negative regulator of SOCE complexes in differentiated PC12 cells.

\section{Conclusion}

In summary, we have shown that the overexpression of FAM3A attenuated the glutamate-induced toxicity in NGF-differentiated PC12 cells. These effects of FAM3A might be dependent on its regulation of intracellular $\mathrm{Ca}^{2+}$ homeostasis. FAM3A not only inhibited $\mathrm{ER} \mathrm{Ca}^{2+}$ release via inhibition of the surface expression of mGluR1/5, but also attenuated SOCE-mediated $\mathrm{Ca}^{2+}$ influx by disrupting the STIM1-Orai1 complex.

\section{Acknowledgements}

This work was supported by the National Natural Science Foundation of China (No. 81601316). The authors would like to thank Dr. Terry Chen for his technical support for the experiments and the preparation of the manuscript.

\section{Disclosure Statement}

The authors report no conflicts of interest. 


\section{Cellular Physiology Cell Physiol Biochem 2017;44:2029-2041 \begin{tabular}{l|l|l} 
and Biochemistry Published onlIne: December 12, 2017 & $\begin{array}{l}\text { (c) } 2017 \text { The Author(s). Published by S. Karger AG, Basel } \\
\text { www.karger.com/cpb }\end{array}$ \\
\hline
\end{tabular}}

\section{References}

1 Feigin VL, Forouzanfar MH, Krishnamurthi R, Mensah GA, Connor M, Bennett DA, Moran AE, Sacco RL, Anderson L, Truelsen T, O’Donnell M, Venketasubramanian N, Barker-Collo S, Lawes CM, Wang W, Shinohara Y, Witt E, Ezzati M, Naghavi M, Murray C: Global and regional burden of stroke during 19902010: findings from the Global Burden of Disease Study 2010. Lancet 2014;383:245-254.

-2 Shirley R, Ord EN, Work LM: Oxidative Stress and the Use of Antioxidants in Stroke. Antioxidants (Basel) 2014;3:472-501.

3 Allen CL, Bayraktutan U: Oxidative stress and its role in the pathogenesis of ischaemic stroke. Int J Stroke 2009;4:461-470.

4 Sato Y: Abnormal bone and calcium metabolism in patients after stroke. Arch Phys Med Rehabil 2000;81:117-121.

5 Mehta SL, Manhas N, Raghubir R: Molecular targets in cerebral ischemia for developing novel therapeutics. Brain Res Rev 2007;54:34-66.

6 Zhang J, Yang J, Zhang C, Jiang X, Zhou H, Liu M: Calcium antagonists for acute ischemic stroke. Cochrane Database Syst Rev 2012;10.1002/14651858.CD001928.pub2CD001928.

7 Chen T, Fei F, Jiang XF, Zhang L, Qu Y, Huo K, Fei Z: Down-regulation of Homer1b/c attenuates glutamatemediated excitotoxicity through endoplasmic reticulum and mitochondria pathways in rat cortical neurons. Free Radic Biol Med 2012;52:208-217.

8 Chen T, Yang YF, Luo P, Liu W, Dai SH, Zheng XR, Fei Z, Jiang XF: Homer1 knockdown protects dopamine neurons through regulating calcium homeostasis in an in vitro model of Parkinson's disease. Cell Signal 2013;25:2863-2870.

-9 Levite M: Glutamate receptor antibodies in neurological diseases: anti-AMPA-GluR3 antibodies, antiNMDA-NR1 antibodies, anti-NMDA-NR2A/B antibodies, anti-mGluR1 antibodies or anti-mGluR5 antibodies are present in subpopulations of patients with either: epilepsy, encephalitis, cerebellar ataxia, systemic lupus erythematosus (SLE) and neuropsychiatric SLE, Sjogren's syndrome, schizophrenia, mania or stroke. These autoimmune anti-glutamate receptor antibodies can bind neurons in few brain regions, activate glutamate receptors, decrease glutamate receptor's expression, impair glutamate-induced signaling and function, activate blood brain barrier endothelial cells, kill neurons, damage the brain, induce behavioral/ psychiatric/cognitive abnormalities and ataxia in animal models, and can be removed or silenced in some patients by immunotherapy. J Neural Transm (Vienna) 2014;121:1029-1075.

-10 Besancon E, Guo S, Lok J, Tymianski M, Lo EH: Beyond NMDA and AMPA glutamate receptors: emerging mechanisms for ionic imbalance and cell death in stroke. Trends Pharmacol Sci 2008;29:268-275.

11 Zhu Y, Xu G, Patel A, McLaughlin MM, Silverman C, Knecht K, Sweitzer S, Li X, McDonnell P, Mirabile R, Zimmerman D, Boyce R, Tierney LA, Hu E, Livi GP, Wolf B, Abdel-Meguid SS, Rose GD, Aurora R, Hensley P, Briggs M, Young PR: Cloning, expression, and initial characterization of a novel cytokine-like gene family. Genomics 2002;80:144-150.

12 Yang J, Guan Y: Family with sequence similarity 3 gene family and nonalcoholic fatty liver disease. J Gastroenterol Hepatol 2013;28 Suppl 1:105-111.

13 Li J, Zhang Y, Zhao MM: [The role of PANDER in the pathogenesis of diabetes]. Sheng Li Ke Xue Jin Zhan 2008;39:339-342.

14 Wang C, Chi Y, Li J, Miao Y, Li S, Su W, Jia S, Chen Z, Du S, Zhang X, Zhou Y, Wu W, Zhu M, Wang Z, Yang H, Xu G, Wang S, Yang J, Guan Y: FAM3A activates PI3K p110alpha/Akt signaling to ameliorate hepatic gluconeogenesis and lipogenesis. Hepatology 2014;59:1779-1790.

15 Zhou Y, Jia S, Wang C, Chen Z, Chi Y, Li J, Xu G, Guan Y, Yang J: FAM3A is a target gene of peroxisome proliferator-activated receptor gamma. Biochim Biophys Acta 2013;1830:4160-4170.

-16 Song Q, Gou WL, Zhang R: FAM3A Protects HT22 Cells Against Hydrogen Peroxide-Induced Oxidative Stress Through Activation of PI3K/Akt but not MEK/ERK Pathway. Cell Physiol Biochem 2015;37:1431-1441.

-17 Song Q, Gou WL, Zhang R: FAM3A attenuates ER stress-induced mitochondrial dysfunction and apoptosis via CHOP-Wnt pathway. Neurochem Int 2016;94:82-89.

18 Westerink RH, Ewing AG: The PC12 cell as model for neurosecretion. Acta Physiol (Oxf) 2008;192:273-285.

19 Tischler AS, Perlman RL, Morse GM, Sheard BE: Glucocorticoids increase catecholamine synthesis and storage in PC12 pheochromocytoma cell cultures. J Neurochem 1983;40:364-370. 


\section{Cellular Physiology Cell Physiol Biochem 2017;44:2029-2041 \begin{tabular}{ll|l} 
and Biochemistry & DOI: 10.1159/000485943 & $\begin{array}{l}\text { (c) } 2017 \text { The Author(s). Published by S. Karger AG, Basel } \\
\text { www.karger.com/cpb }\end{array}$
\end{tabular}}

20 Chen T, Zhu J, Zhang C, Huo K, Fei Z, Jiang XF: Protective effects of SKF-96365, a non-specific inhibitor of SOCE, against MPP+-induced cytotoxicity in PC12 cells: potential role of Homer1. PLoS One 2013;8:e55601.

-21 Hartmann J, Karl RM, Alexander RP, Adelsberger H, Brill MS, Ruhlmann C, Ansel A, Sakimura K, Baba Y, Kurosaki T, Misgeld T, Konnerth A: STIM1 controls neuronal Ca(2)(+) signaling, mGluR1-dependent synaptic transmission, and cerebellar motor behavior. Neuron 2014;82:635-644.

22 Wang C, Burkhardt BR, Guan Y, Yang J: Role of pancreatic-derived factor in type 2 diabetes: evidence from pancreatic beta cells and liver. Nutr Rev 2012;70:100-106.

-23 Chen Z, Wang J, Yang W, Chen J, Meng Y, Geng B, Cui Q, Yang J: FAM3A mediates PPARgamma's protection in liver ischemia-reperfusion injury by activating Akt survival pathway and repressing inflammation and oxidative stress. Oncotarget 2017;8:49882-49896.

24 Chi Y, Li J, Li N, Chen Z, Ma L, Peng W, Pan X, Li M, Yu W, He X, Geng B, Cui Q Liu Y, Yang J: FAM3A enhances adipogenesis of 3T3-L1 preadipocytes via activation of ATP-P2 receptor-Akt signaling pathway. Oncotarget 2017;8:45862-45873.

25 Mattson MP: Calcium as sculptor and destroyer of neural circuitry. Exp Gerontol 1992;27:29-49.

26 Choi DW: Ionic dependence of glutamate neurotoxicity. J Neurosci 1987;7:369-379.

27 Stringham JM, Stringham NT: Nitric Oxide and Lutein: Function, Performance, and Protection of Neural Tissue. Foods 2015;4:678-689.

28 Phillips L, Toledo AH, Lopez-Neblina F, Anaya-Prado R, Toledo-Pereyra LH: Nitric oxide mechanism of protection in ischemia and reperfusion injury. J Invest Surg 2009;22:46-55.

29 Raab-Graham KF, Workman ER, Namjoshi S, Niere F: Pushing the threshold: How NMDAR antagonists induce homeostasis through protein synthesis to remedy depression. Brain Res 2016;1647:94-104.

30 Luo P, Fei F, Zhang L, Qu Y, Fei Z: The role of glutamate receptors in traumatic brain injury: implications for postsynaptic density in pathophysiology. Brain Res Bull 2011;85:313-320.

-31 Bordi F, Ugolini A: Group I metabotropic glutamate receptors: implications for brain diseases. Prog Neurobiol 1999;59:55-79.

-32 Chen T, Cao L, Dong W, Luo P, Liu W, Qu Y, Fei Z: Protective effects of mGluR5 positive modulators against traumatic neuronal injury through PKC-dependent activation of MEK/ERK pathway. Neurochem Res 2012;37:983-990.

33 Chen T, Zhang L, Qu Y, Huo K, Jiang X, Fei Z: The selective mGluR5 agonist CHPG protects against traumatic brain injury in vitro and in vivo via ERK and Akt pathway. Int J Mol Med 2012;29:630-636.

34 Sheffler DJ, Gregory KJ, Rook JM, Conn PJ: Allosteric modulation of metabotropic glutamate receptors. Adv Pharmacol 2011;62:37-77.

-35 Enz R: Metabotropic glutamate receptors and interacting proteins: evolving drug targets. Curr Drug Targets 2012;13:145-156.

-36 Welsby P, Rowan M, Anwyl R: Nicotinic receptor-mediated enhancement of long-term potentiation involves activation of metabotropic glutamate receptors and ryanodine-sensitive calcium stores in the dentate gyrus. Eur J Neurosci 2006;24:3109-3118.

37 Simpson PB, Challiss RA, Nahorski SR: Chronic activation of muscarinic and metabotropic glutamate receptors down-regulates type I inositol 1, 4,5-trisphosphate receptor expression in cerebellar granule cells. J Neurochem 1994;63:2369-2372.

-38 Lonart G, Alagarsamy S, Johnson KM: (R,S)-alpha-amino-3-hydroxy-5-methylisoxazole-4-propionic acid (AMPA) receptors mediate a calcium-dependent inhibition of the metabotropic glutamate receptorstimulated formation of inositol 1, 4,5-trisphosphate. J Neurochem 1993;60:1739-1745.

-39 Joseph SK, Hajnoczky G: IP3 receptors in cell survival and apoptosis: Ca2+ release and beyond. Apoptosis 2007;12:951-968.

40 Majewski L, Kuznicki J: SOCE in neurons: Signaling or just refilling? Biochim Biophys Acta 2015;1853:19401952.

41 Li Y, Song J, Liu X, Zhang M, An J, Sun P, Li D, Jin T, Wang J: High expression of STIM1 in the early stages of diffuse axonal injury. Brain Res 2013;1495:95-102.

42 Henke N, Albrecht P, Pfeiffer A, Toutzaris D, Zanger K, Methner A: Stromal interaction molecule 1 (STIM1) is involved in the regulation of mitochondrial shape and bioenergetics and plays a role in oxidative stress. J Biol Chem 2012;287:42042-42052. 


\section{Cellular Physiology Cell Physiol Biochem 2017;44:2029-2041 \begin{tabular}{l|l|l} 
DOI: 10.1159/000485943 & $\begin{array}{l}\text { O 2017 The Author(s). Published by S. Karger AG, Basel } \\
\text { www.karger.com/cpb }\end{array}$ \\
\hline
\end{tabular}}

43 Rao W, Zhang L, Su N, Wang K, Hui H, Wang L, Chen T, Luo P, Yang YF, Liu ZB, Fei Z: Blockade of SOCE protects HT22 cells from hydrogen peroxide-induced apoptosis. Biochem Biophys Res Commun 2013;441:351-356.

44 Li X, Chen W, Zhang L, Liu WB, Fei Z: Inhibition of store-operated calcium entry attenuates MPP(+)-induced oxidative stress via preservation of mitochondrial function in PC12 cells: involvement of Homer1a. PLoS One 2013;8:e83638.

45 Frischauf I, Fahrner M, Jardin I, Romanin C: The STIM1: Orai Interaction. Adv Exp Med Biol 2016;898:2546.

46 Luik RM, Wang B, Prakriya M, Wu MM, Lewis RS: Oligomerization of STIM1 couples ER calcium depletion to CRAC channel activation. Nature 2008;454:538-542.

47 Luik RM, Wu MM, Buchanan J, Lewis RS: The elementary unit of store-operated Ca2+ entry: local activation of CRAC channels by STIM1 at ER-plasma membrane junctions. J Cell Biol 2006;174:815-825.

-48 Zhang SL, Yeromin AV, Zhang XH, Yu Y, Safrina O, Penna A, Roos J, Stauderman KA, Cahalan MD: Genomewide RNAi screen of $\mathrm{Ca}(2+)$ influx identifies genes that regulate $\mathrm{Ca}(2+)$ release-activated $\mathrm{Ca}(2+)$ channel activity. Proc Natl Acad Sci U S A 2006;103:9357-9362.

49 Martin AC, Willoughby D, Ciruela A, Ayling LJ, Pagano M, Wachten S, Tengholm A, Cooper DM: Capacitative $\mathrm{Ca} 2+$ entry via Orai1 and stromal interacting molecule 1 (STIM1) regulates adenylyl cyclase type 8. Mol Pharmacol 2009;75:830-842.

50 Yu F, Sun L, Machaca K: Constitutive recycling of the store-operated Ca2+ channel Orai1 and its internalization during meiosis. J Cell Biol 2010;191:523-535.

51 Yu F, Sun L, Machaca K: Orai1 internalization and STIM1 clustering inhibition modulate SOCE inactivation during meiosis. Proc Natl Acad Sci U S A 2009;106:17401-17406.

52 Park CY, Shcheglovitov A, Dolmetsch R: The CRAC channel activator STIM1 binds and inhibits L-type voltage-gated calcium channels. Science 2010;330:101-105.

53 Wang Y, Deng X, Mancarella S, Hendron E, Eguchi S, Soboloff J, Tang XD, Gill DL: The calcium store sensor, STIM1, reciprocally controls Orai and CaV1.2 channels. Science 2010;330:105-109. 